\title{
DESAFIOS E POSSIBILIDADES DO ENSINO DE LITERATURA PARA ESTUDANTES DO ENSINO MÉDIO NA ERA TIC
}

\author{
ARTIGO ORIGINAL \\ LISBOA, Adébio de Jesus Ribeiro ${ }^{1}$ \\ CAMARGO, Aline Pinheiro Lima ${ }^{2}$ \\ SANTOS, Vinícius da Silva ${ }^{3}$ \\ SILVA, Maria Nazaré Ribon ${ }^{4}$ \\ OLIVEIRA, Ivana Esteves Passos de ${ }^{5}$
}

LISBOA, Adébio de Jesus Ribeiro. Et al. Desafios e possibilidades do ensino de literatura para estudantes do Ensino Médio na era TIC. Revista Científica Multidisciplinar Núcleo do Conhecimento. Ano 05, Ed. 06, Vol. 09, pp. 55-73. Junho de ISSN: 2448-0959, Link de acesso: https://www.nucleodoconhecimento.com.br/educacao/ensino-de-literatura

\footnotetext{
${ }^{1}$ Mestre em Ciência Tecnologia e Educação pela Faculdade do Vale do Cricaré; Graduado em Letras-Português pela Universidade Metropolitana de Santos UNIMES.

${ }^{2}$ Mestre em Ciência Tecnologia e Educação.

${ }^{3}$ Mestrando em Ciências Tecnologia e Educação pela Faculdade Vale do Cricaré em São Mateus - ES; Licenciado em Biologia.

${ }^{4}$ Mestre em Educação.

${ }^{5}$ Doutorado em Letras. Mestrado em Mestrado em Estudos Literários. Especialização em Marketing. Graduação em Comunicação Social.
} 


\section{RESUMO}

Este artigo explora a temática acerca dos desafios e possibilidades acerca do ensino de literatura para estudantes do Ensino Médio na ERA TIC. Sua relevância científica encontra-se no fato de que irá contribuir para ampliar as propostas metodológicas voltadas para o ensino formal de literatura, utilizando as novas ferramentas tecnológicas de informação e de comunicação disponíveis. Sua relevância social se apresenta na condição de que irão proporcionar ao público em geral, conhecimentos sobre as possibilidades que se apresentam aos estudantes que desejam aprimorar seus saberes e ampliar seus conhecimentos literários. Trata-se de uma pesquisa bibliográfica, fundamentada em autores renomados sobre o assunto, vinculando a didática às novas oportunidades de ensino e de aprendizagem e à necessidade de se ter instrumentos capazes de atender a um público singular, como os estudantes do Ensino Médio. Busca explorar o sentido do ensino de Literatura e como elemento de formação da cidadania, do autoconhecimento, equanimizador entre a phronesis e a espisteme. As conclusões a que foi possível chegar são de que a ausência de metodologias específicas que atendam às exigências dos campos de atuação docente e, mais especificamente, à psicologia do público-alvo, torna o ensino de literatura para o Ensino Médio, um desafio. No entanto, criam-se possibilidades reais que pode destacar-se a oportunidade de se inventar e reinventar novas metodologias ativas, inovadoras e de grande impacto educacional, acadêmico e social.

Palavras-Chave: Ensino de literatura, estudantes do Ensino Médio, era TIC.

\section{INTRODUÇÃO}

Ensinar literatura nunca foi uma missão fácil para um mestre, porque é algo que foge ao controle absoluto daquele que maneja a escrita e deixa livre para interpretar, a seu gosto, aquele que executa a leitura do material produzido pelo autor. Isto sugere, já de antemão que, sem um profundo conhecimento sociológico, nenhum professor de literatura que se preze, pode dar-se ao luxo de considerar-se um pensador da literatura e tal assertiva provoca um grande mal estar nos procedimentos didáticos. Então, afinal, do que se fala de fato, em uma aula sobre literatura? Fala-se da obra, 
que é produto do autor, ou fala-se do tempo histórico e de acontecimentos únicos que atravessaram de uma forma espetacular determinado autor. Portanto, o resultado é algo que não pode ser compreendido em seu tempo. , Estranhamente, então a literatura continuará a desafiar os expectadores de eras inimagináveis por aquelas criaturas?

Assim, eis que temos um paradoxo: $O$ que, de fato, nos atrai, em um estudo acerca da literatura? A criatura ou o criador? Este é um produto de seu tempo, um ser que já nasceu como o sábio da velha lenda chinesa, um velho-criança, alguém que teve que arcar com o peso ad absurdum de toda a cultura que o antecedeu. No entanto, aquilo que nasceu de suas entranhas mentais, ousou sonhar o esplendor da juventude, como diria Nietzsche, sonhou o futuro que não podia estar muito longe de si mesma, porque desconhecia qualquer coisa diferente de seu mundo e de seu tempo. Logo, tem-se outro embaraço, porque tudo aquilo que se enxerga, por meio dos olhos do artista visionário, pode não ser nada mais que uma interpretação do desejo pessoal de que assim o fosse, uma ilusão, da mesma maneira que uma criança vê animais formados por nuvens no céu.

Neste sentido, temos outro elemento questionador: O que ocorre se negarmos a esta ilusão e passarmos a enfrentar a vida sem este véu dourado da imaginação que a literatura nos traz? O que ocorre se não nos permitirmos alcançar voos encontrar alento para o existir cada dia que nos segue com mais e mais felicidade? O que ocorre se negarmos a dor e tudo o mais que nos limita, desafia e aproxima da extinção? Esta, talvez seja a resposta para o fato de se ensinar literatura com tamanha paixão que se termina por contaminar aqueles que assistem às preleções e às aulas. Todos desejam esquecer os seus limites como seres humanos e atravessar o reino de Lettes, sem cair em suas águas mais profundas. Não há mulher que não tenha desejado, um dia, ser amada como o foi a Eva, de John Milton e não há homem que não deseje encontrar para si, uma Penélope, como a que deu a Ulisses, o poeta grego, Homero.

Sendo assim, tem-se que ensinar literatura não é uma profissão é a arte de encantar e humanizar. Pois, com arte ensiná-la é uma missão, em que se desperta aquilo que há de mais sagrado no humano. Aprendê-la é a capacidade de ver o que não existe 
no outro e fazer com que este desejo se transforme em uma realidade concreta. Portanto, ela é a oportunidade de ir além de tudo que pode ser conquistado e captado pela capacidade subjetiva humana. $O$ artista fala para além de si mesmo e seu intérprete, anos, décadas, séculos e milênios depois fala por ele, para além de seu tempo histórico e filosófico. Mesmo assim, não se sabe o que está a ensinar e nem porque, e esta atitude rebelde não o transforma em um néscio, antes, pelo contrário, é nesta busca por uma resposta para aquilo que faz que termine por fazer melhor.

Ensinar envolve trocas simbólicas. Infelizmente, estas nem sempre são as mais intrigantes de todas, porque, para se ensinar bem, deve ser capaz de iludir com tanta efusão que o encanto dos outros contamina ao feiticeiro e quanto mais intenso. Assim, esta contrapartida intensifica a paixão e o desejo por aquilo que se executa. Paganini jamais seria capaz de ensinar a alguém a tocar violino com apenas uma corda, ignorando uma orquestra atônita e um maestro sem inspiração pelo ocasional. Da mesma forma, um professor não pode realizar o milagre de fazer alguém a gostar de literatura, o máximo que ele pode chegar é a obrigar seus alunos a lerem. No entanto, ele pode ler com tanta paixão, com tanto sentimento, com tamanha potência que desperte o desejo de que venham a igualar-se a ele na leitura. E, ao fazê-lo, descobrem que havia algo mais escondido naquela leitura e que não estava no texto, estava na força da paixão, da sensibilidade imposta pelo leitor.

Com a chegada de um período histórico em que se convencionou chamar de PósModernidade e que mais sensato seria chamá-la de atualidade. Isto porque cada tempo guarda o seu grau singular de particularidades. Junto com o tempo um sem fim de desafios que são interpretados como dificuldades a serem superadas pela razão lógica. Assim é que surgem as novas formas de ensinar e de aprender. Isto faz com que a didática seja uma ciência dinâmica, em seu próprio campo de estudos. Assim sendo, ensinar literatura neste momento tornou-se mais difícil e não mais complexo como se deseja fazer crer.

A formação de alunos leitores se dá pelo exemplo daqueles que admiramos. O mais interessante disso é que na palavra e no sentimento de admiração esconde um eufemismo social, que é o sentimento execrável da inveja. Quando alguém vê outro a 
ler determinado livro com imensa paixão e devoção, fica curioso para saber que segredos estão escondidos naquelas páginas. Assim, em seu inconsciente martela a ideia de que o sucesso, que tal figura possui, é devido ao segredo que está ali, oculto a ele, mas que também pode chegar até lá, fazendo o mesmo caminho que seu mentor.

E agora perguntamos o porquê de, na atualidade o livro, os romances, os contos, as crônicas, as novelas não despertarem mais tanto a atenção dos adolescentes e nem mesmo das crianças. A literatura encontrou depois de milênios um adversário tão poderoso quanto ela o foi para a contação de histórias na Antiguidade: o celular, a internet, o computador pessoal. Estes instrumentos mágicos e encantadores atraem de tal forma a atenção dos adultos que, desde muito cedo, as crianças querem fazer parte deste mundo. O bielorusso L. S. Vygotsky foi um dos primeiros a entender que o homem é um animal que segue padrões, cópia formas de ação e de reação. S. Freud, de igual forma, já havia alertado para isto. Portanto, tem-se que a formação de alunos leitores é uma reprodução de um comportamento admirado.

Sendo assim, o séquito e os objetos encantadores resultantes do advento da ERA TIC fizeram surgir muitos desafios para o ensino formal de literatura. Estes, entretanto, não podem ser encarados como dificuldades, porque, ao tê-los na conta de desafios didático-pedagógicos tem-se, como apresenta-nos Heráclito de Éfeso, a possibilidade de criação de novos métodos didático-pedagógicos, utilizando-se para isto, as mesmas ferramentas que [a priori] impossibilitam um ensino à altura das exigências do Século XXI.

Os desafios que se mostram, em um primeiro instante, estão relacionados com o planejamento didático das atividades programáticas, que devem ser, antes de tudo, pragmáticas, úteis. Os planos de aula, de intervenção e de suporte devem estar no nível da proporção do avanço e do interesse dos estudantes. Tudo isto, para motiválos e desafiá-los e não o contrário, como tem ocorrido. Pois, caso o professor não os seduzir e encantá-los com seus ensinamentos, ele pode se tornar um candidato sério a perder a batalha para seus estudantes e seus brinquedos encantadores. 
No campo das possibilidades, o estudante pode ter acesso à obra em tempo real, assim como pode acessar tudo o que a envolve, o autor, sua história de vida, comentários, entrevistas, análises literárias, estudos temporais, análises dos elementos tangíveis e intangíveis que cercaram seu mundo intra e extra psíquico. A internet coloca à disposição do profissional um acervo jamais pensado antes na história humana, em vários idiomas, favorecendo além do ensino e da aprendizagem da literatura e das obras, um intercâmbio linguístico, inigualável.

Assim que, o ensino da literatura deixa de ser um desafio para o professor contemporâneo, pode se transformar em uma poderosa ferramenta de formação sociológica e filosófica, pois pode conectar-se ao seu estudante, aos tempos distintos e ás culturas distintas, sem que tenha que sair de seu espaço físico. Para isto, vai valer de seu esforço intelectual e de sua formação didática, aliando tudo isto a uma paixão sem medidas pelo ensino e pela arte literária.

\section{AS TIC's E O ENSINO DE LITERATURA}

O ensino, de maneira geral, é vinculado às demandas, às possibilidades e aos desafios que cada momento histórico oferece e/ou coloca como consequência dos avanços proporcionados pela sociedade. Tudo o que é posto em evidência mostra-se ao primeiro instante como um elemento dificultador, impossibilitador de uma superação pelos atores responsáveis pela formação dos estudantes.

Mas, eis que toda esta forma de pensamento revela-se como uma forma de resistência, porque toda mudança na estrutura do ensino e da aprendizagem obriga ao professor a buscar aperfeiçoar-se, a adequar-se ao necessário que faz-se exigência notória e, com o ensino de literatura na era das Tecnologias da Informação e Comunicação (TIC's) deram-se o mesmo. Isto porque, elas surgem como um novo elemento que se incorpora ao corpo do saber, o que passa a exigir novas didáticas, agora ajustadas a atender às exigências que sua existência provoca. Nisto, o professor deve buscar pensar novas metodologias que permitam o ensino de literatura, de acordo com a proposta curricular, adequar as metodologias antigas, e, sobretudo, buscando formas inovadoras de ensinar e de aprender, uma vez que, a 
inserção da educação na ERA TIC é um fenômeno irreversível. Assim sendo, não cabe questionar seu valor e que condições dar-se-ão a produção dos saberes de aí por diante, porque o que a sociedade coloca como objetivo para a escola é a formação de um cidadão ajustado a seu tempo e às suas mudanças particulares.

Segundo Caniçali e Souza (2018, p. 04),

ERA TIC não é um simples conceito abstrato, é uma realidade histórica, presente, crescente e permanente. Representa um complexo paradigma abstrato que absorveu a todos (...) sem distinção, até mesmo aqueles que se encontram, literalmente, à margem dos processos de inovações tecnológicas estão, de alguma maneira, imersos nesta era de transformações.

E quem ousar não se adaptar estará literalmente fora do processo. Portanto, cabe ao professor de Literatura ajustar seu modo de ensino e muito mais que isto, orientar seus aprendizes formas e estratégias para aproveitarem, ao máximo possível, as condições de aprendizagem que as TIC's oferecem. Para que isto aconteça, será necessário dinamizar as categorias de ensino, absorver o que esteja possível de alcançar e considerar que, cada vez que o professor se nega a adaptar-se e a seus aprendizes às mudanças estruturais que a sociedade impõe, corre o risco de produzir um indivíduo incapaz de adaptar-se socialmente e, isto é o que a Literatura Clássica cuida de mostrar, com profunda maestria em seus campos de exposição.

O povo brasileiro não possui hábitos marcantes de leitura. Basta constatar que, em média, um cidadão brasileiro lê, sem a menor modéstia, 1,8 livros por ano. No entanto, dizer que não lê é uma coisa, que não se condiz com a realidade; o problema está no hábito fino, sagaz de executar a leitura de textos clássicos, de interpretá-los à luz da razão, da lógica e da ciência erudita. A este respeito o autor Silva (2016, p. 44) diz que este problema tem ocorrido porque "não há uma correspondência entre o conceito de Literatura apregoado pelos docentes e os textos a que os alunos têm acesso, leem, procuram, comentam, indicam". 
Depreende-se aqui, que existe uma confusão de línguas e, para ser mais técnico e didático-pedagógico, há uma ausência declarada de uma metodologia de ensino que atenda às reais necessidades do ensino de Literatura e às ânsias dos estudantes. Pois, cada objeto exige uma metodologia específica a ser aplicada sobre seu conteúdo, visando atender às demandas de aprendizagem de estudantes com características singulares.

A ERA TIC e as TIC's mais aproximaram os homens da literatura que dela afastaram como se quer acreditar os mais céticos e pessimistas. Antes deste momento histórico, os grandes clássicos estavam restritos às grandes bibliotecas, que ficam localizadas nas regiões metropolitanas e para ajudar nesta argumentação, é fato sabido que $75 \%$ das escolas de ensino fundamental, no Brasil, não possuem bibliotecas. No máximo [quando há] é o famoso Cantinho da Leitura, em que se encontram algumas enciclopédias ultrapassadas.

Com a inovação tecnológica e a possibilidade de conexão com a rede mundial de computadores (a Internet), o professor e os estudantes podem ler, simultaneamente, grandes obras da literatura universal, em suas línguas originais, bem como podem assistir a vídeo-aulas sobre os autores, os temas, as respectivas épocas e os locais onde se passa a obra. Como exemplo podemos citar o Sítio eletrônico Domínio Público e o Google Livros dentre outros, que disponibilizam milhares de obras para leitores e pesquisadores.

Disto isto, pode-se compreender que o grande desafio que se coloca é com relação à didática a ser aplicada, uma vez que, nela não exista metodologia e não há nada que pese contra isto, métodos e estratégias de ensino somente podem ser desenvolvidos por meio de pesquisa aplicada. Em atendimento às necessidades, cria-se os mecanismos que possam garantir suporte ao surgimento de métodos adequados à realidade objetiva. Ao mesmo tempo em que pode ser confrontado como um problema que exige solução [imediata] apresenta-se como uma possibilidade de ampliação da práxis pedagógica. 
Aborda-se, aqui, este termo fundamentando o pensamento docente em Caniçali e Souza $(2018$, p. 07) para quem,

O termo práxis é um conceito muito amplo porque está inserido em um ambiente que envolve a prática e a teoria, representando não uma ação isolada, se não conjunta, que produz uma relação de reciprocidade e simultaneidade entre a teoria e a prática. O que realmente há de mais interessante é que ela somente acontece no âmbito do trabalho empírico, o que the confere um caráter amplamente científico e confiável. Um mestre e/ou um professor que pode dizer que realiza durante seus trabalhos docentes uma práxis é alguém que tem amplo domínio do conhecimento teórico e empírico, bem como da aplicabilidade dos mesmos em relação aos rumos que direcionam as atividades do ensino e da aprendizagem.

Pode-se compreender do exposto que as inovações vindouras ao ambiente escolar devem ser anexadas ao rol de atividades docentes como elementos potenciais que apresentam seu grau clássico e ordinário de dificuldades. Pois, são a partir da superação destes desafios que as ciências pedagógicas se permitem o avanço didático necessário para enfrentar o desafio natural de ensinar àqueles que desejam aprender. Com o ensino da Literatura não se dá de forma distinta, uma vez que se trata de um ramo das ciências literárias que possui um objeto de estudo, métodos de análises, interpretação e compreensão próprios, um escopo, princípios e normas específicos que são aplicadas às obras literárias, com o intuito de extrair o que de melhor elas possam oferecer a toda a sociedade.

\section{DESAFIOS E POSSIBILIDADES PARA O ENSINO DE LITERATURA}

\section{NA ERA TIC}

A Literatura é uma fonte muita ampla de conhecimentos, fruição e, sobretudo, prazer. No entanto, para que tudo isto seja alcançado pelo estudante, faz-se necessário que alguns obstáculos sejam superados, em conjunto com o professor, a fim de que além de alcançarem informações úteis, produzam-nas em quantidade e qualidade viável. 
Esta gama de informações permite que, além da aquisição do conhecimento de mundo por parte dos estudantes, permite, sobretudo, o autoconhecimento, fato que possibilita que eles arrisquem-se a explorar uma infinidade de obras literárias, clássicas ou não, com diferentes características e temas e ao professor, agregar ao escopo da sua didática mais um método eficiente de ensino de literatura e de hábito de ler.

Não se pode cair na conduta inocente de que o ensino de Literatura, criação de hábitos de leitura e que, historicamente, representou uma luta pela superação da dicotomia entre saber ler e saber interpretar/compreender os textos lidos sobrexiste toda uma construção vinculada a poder aquisitivo, acesso à leitura, grau de instrução familiar, cultura em si, em seu sentido mais amplo, expectativas de vida, visão de futuro e manutenção do poder.

Os desafios, visíveis e invisíveis, que são postos ao professor de literatura, especialmente, para aquele que atua com seriedade e compromisso são inúmeros, o que, na mesma direção, as possibilidades mostram-se na mesma intensidade. Isto se dá, porque a prática do ensino e da aprendizagem da Literatura constitui-se como um ato político. Ato político, em seu sentido semântico original, nada mais é do que uma prática cidadã, ou que pode proporcionar a formação para a cidadania.

Neste sentido não se pode ser ingênuo, ao crer que o mero hábito de ler transforma alguém em agente de transformação social, o que se explora neste sentido é a possibilidade de ampliação do entendimento e interpretação do real e em consonância com Jaspers (1991, p. 65), "todo conhecimento é interpretação". Tem-se que, a partir do instante em que ambos os indivíduos (professor e estudante) imergem no processo de interpretação dos textos, das obras, de suas proposições estão a produzir conhecimentos, automaticamente, estão a promover o avanço das ciências, criando novas possibilidades, superando, com isto, os desafios que foram colocados a eles pela sociedade e pela própria ânsia da descoberta investigativa.

A este respeito, S. P. Mikúlinskiy revela que, 
O caminho para o descobrimento dos mecanismos e regularidades do desenvolvimento da ciência, pelo qual entendemos, em primeiro lugar e de maneira principal, a criação de novo conhecimento, não consiste em limitar a investigação, a princípio, exclusivamente ao campo do desenvolvimento lógico dos conceitos científicos, para a qual nos chama o internalismo, nem em reduzir a explicação da história da ciência, exclusivamente às condições sociais e econômicas, o que de modo infrutífero, tratam de fazer os externalistas (MIKULINSKIY, 1985, p. 14).

O que o autor procura expor é que todo objeto, ao ser colocado como fenômeno, passível de ser estudado, revela intrigantes particularidades e singularidades, estas que o caracterizam e conformam e que, estas necessitam ser esclarecidas, a fim de que se possa aproximar, ao máximo, da verdade essencial, presente no processo. No caso da Literatura, tudo se torna mais desafiador, porque as obras literárias clássicas reúnem não apenas o que o autor tem de melhor [e de pior], como reúne, ainda, o que a sociedade, o momento histórico, a cultura e a fé possuem de mais profundo [e de mais superficial e raso].

Não se pode deixar levar pela ingenuidade e crer que os desafios são vencidos e restam somente possibilidades. Ambos os processos são uma constante, que viajam em mão dupla, paradoxalmente proporcionando oportunidades futuras, em que os desafios proporcionam condições de realizações e superações e estas, por sua vez, criam novos desafios, porque a curiosidade científica é [e dever ser de forma contínua] a mola propulsora dos procedimentos de ensino e de aprendizagem.

Referente ao ensino, Vidal Nunes (2018) argumenta que,

A forma de se dirigir ao leitor pode ocorrer de várias maneiras. Há dois aspectos importantes a considerar: um didático e outro pedagógico. $\mathrm{O}$ didático vincula-se ao esforço que o autor do texto faz para torná-lo compreensível. Trabalha-se de tal maneira que todos os meios que favoreçam entendimento do leitor e a legibilidade do texto devem ser usados. Neste sentido, também se leva em conta possíveis objeções que 
poderia ocorrer por parte do leitor. Articulada à primeira, temos a função pedagógica, que visa uma identificação do leitor com as convicções que o autor expõe. O que se pretende é uma conversão do leitor, uma mudança em suas representações, com um discurso que para ele possa tornar-se significativo. Essas considerações não apenas devemos levar em conta no nosso processo de leitura, mas também em nossa atividade (NUNES, 2018, p. 18).

O autor esclarece que, muito mais que estar preparado para lecionar a matéria, o professor há que estar engajado no conhecimento acerca dos procedimentos didáticos e pedagógicos, relacionados ao que se pretende ensinar. E, sobretudo, ter como proposta o que o estudante irá aprender e compreender, ainda, todo seu escopo psicológico, sempre tendo muito claro que ele irá apresentar variados graus de resistência, que podem ser perceptíveis ou não, declaradas ou veladas.

Tudo isto conduz ao esclarecimento de que neste novo cenário pedagógico, em que um novo elemento foi incorporado. Portanto, a formação permanente do professor e que o interesse do estudante se faz de suma relevância. Para isto, é necessário anexar aos seus respectivos espaços de interesse o domínio as ferramentas e técnicas digitais e tudo o que elas possam oferecer como coadjuvante nos processos formais e informais de ensino e de aprendizagem, considerando que

Sem estas mudanças, a tendência da escola é transformar-se em um buraco negro na vida dos indivíduos, o que faz consumir um tempo significativo de sua vida ao não conseguir preparar cidadãos capazes de atuar na sociedade do conhecimento. [Isto porque] à medida em que ela [a escola], impõe uma agenda, que denega e castra a predisposição da aprendizagem que os indivíduos possuem, que não integra o uso das TIC's, [tudo o que ela gera] passa a ser contraprodutivo. Contudo, se persistir nesta direção e continuar preparando profissionais obsoletos irão tornar-se absolutamente dispensável neste novo cenário de inúmeras oportunidades de aprendizagem que vão se descortinando (VALENTE, 2005, p. 95). 
$\mathrm{Na}$ esteira de entendimento do pensamento exposto por J. A. Valente, tem-se que o maior desafio da escola é desejar manter avessa ao que é novo e pode ajudá-la a inovar seus processos de ensino e de aprendizagem. Colocar restrições ao uso indiscriminado das TIC's é necessário, restringir seu uso, é antidemocrático e antididático. Portanto, negar suas potencialidades e as possibilidades que se descortinam é uma completa insanidade e incompetência didático-pedagógica.

É sabido, que os ambientes virtuais de aprendizagem podem auxiliar o estudante e o professor a criar metodologias que possibilitam o avanço do conhecimento e o encontro de crianças e adolescentes com saberes. Caso contrário, ficariam no plano do seu [parco] imaginário, compreendendo que a capacidade de alguém abstrair está vinculada ao seu conhecimento real. Não há como separar a phronesis e a episteme, porque a primeira é consequência da segunda, ou seja, está limitada pela dimensão desta. Logo, quanto mais instrumentos estejam disponibilizados ao estudante, para que explore o saber e, permitam que suas dúvidas sejam expressas, mais potencialidades manifestam, e, isto possibilita maiores descobertas, gerando novos desafios, num ciclo intelectual que não tem fim.

O mais interessante e maravilhoso no ensino da Literatura é a sua capacidade de mobilizar-se e atuar de modo interdisciplinar e transdisciplinar. Isto pode conduzir o professor a um desafio, realmente, interessante: que é o de ensinar ao estudante a dialogar com o texto, da mesma forma que dialoga com outra pessoa de seu convívio pessoal. Esta é ao mesmo tempo uma possibilidade, porque desafia o estudante a encontrar argumentos no texto e contra argumentos em sua mente e vice versa, transformando sua prática em uma práxis.

Esta condição dialética é possível porque, como afirma Tzvetan Todorov (2009, p. 22) "a literatura não nasce no vazio, mas no centro de um conjunto de discursos vivos, compartilhando com eles, numerosas características." Este, caracterizando, em um primeiro instante, como o maior desafio e não como a maior possibilidade para o ensino da Literatura, isto porque para dialogar com o outro que não se faz necessário está presente, mas deve ser interpretado, com isto produzindo conhecimentos, é uma condição de aprender a dialogar consigo mesmo a partir de seu autoconhecimento, o 
que uma vez alcançado, transforma-se em uma ferramenta didática que posta em ação, cria e recria o real.

A ERA TIC trouxe novos elementos que transformaram em ferramentas, postas à disposição pela didática, para que possam ser úteis ao ensino e à aprendizagem de Literatura. Seu caráter é estritamente pragmático, capaz de promover ganhos extraordinários nos campos do saber e do conhecimento, dado que, a phronesis e a episteme não se desenvolve em graus e degraus ascendentes, como já foi demonstrado por Jean Piaget (1896-1980) e por Levi Vygotsky (1896-1934), em que ambos apresentam a ascensão de ambas em forma de espiral, o que já não contempla a realidade didática e cognitiva deste tempo. A este respeito, J. A. Valente (2005) provou que o conhecimento é uma existência que age como uma espiral dupla, imbricada, em que uma está em constante ascendência e outra em constante descendência. No entanto, Caniçali e Souza (2018) ampliam esta teoria e defendem que a phronesis e a episteme representam um vórtice, situado ao nível da visão, perpendicular a ela, atuando em um constante ir e vir e a cada vez que tal movimento ocorre, vai carregado de saberes, conhecimentos e certezas e retornam carregadas de questionamentos, dúvidas. A literatura é o que mais se aproxima de representar este vórtice epistemológico do conhecimento, portanto, seu ensino e sua aprendizagem estão carregados de desafios e possibilidades à disposição de quem ouse enfrentá-los.

Um dos principais desafios para o ensino de literatura é o baixo índice de leitura do povo brasileiro que, segundo uma pesquisa realizada em 2015 e publicada em 2017, pelo Instituto Pró-Livro, não passa de 2,42 livros por ano, isto sem contar com a qualidade do que é consumido por estes leitores. A tabela 2 (infra) traz este quantitativo discriminado por região brasileira.

Outra situação que desperta a atenção é quem são os indivíduos que influenciam os leitores a formarem hábitos de leitura. Uma pesquisa realizada pelo Instituto Pró-Livro, em 2017, mostrou quem mais exerce influência na leitura, no Brasil, conforme mostra tabela 1, abaixo: 
Tabela 1: quem mais exerce influência na formação de leitores

\begin{tabular}{|l|l|}
\hline \begin{tabular}{l} 
Influência no hábito de formação de leitores \\
\hline $\begin{array}{l}\text { Mãe ou figura } \\
\text { materna }\end{array}$
\end{tabular} \\
\hline $\begin{array}{l}\text { Professores } \\
\begin{array}{l}\text { Pais ou figuras } \\
\text { paternas }\end{array}\end{array}$ & $18 \%$ \\
\hline
\end{tabular}

Fonte: GUIMARÃES, 2017, s.p. (Adaptado por LISBOA, 2018).

O que mais chama a atenção nestes resultados não é o fato de as mães e as cuidadoras exercerem tanta influência; é o fato de os professores exercerem tão baixo poder de influência na formação do hábito de leitura. Isto deixa entrever que os próprios professores não demonstram para seus estudantes muito interesse no processo, não realizando a ponte e a motivação para a atividade. Ouro complicador na escola é que, cada professor vive em seu mundo e deixa esta tarefa somente para os professores de Língua Portuguesa e de Literatura, esquecendo que a leitura subjaz como a base de aprendizagem de toda e qualquer disciplina.

Há que esclarecer que o quantitativo de livros lidos não influencia na formação intelectual se a qualidade do material consumido não fizer jus ao que se espera de uma formação epistemológica e gnosiológica adequada.

Tabela 2: Quantidade de livros lidos por leitores de acordo com a região brasileira

\begin{tabular}{|c|c|c|}
\hline \multicolumn{3}{|c|}{$\begin{array}{l}\text { Quantidade de livros lidos por leitores de acordo com a região } \\
\text { brasileira }\end{array}$} \\
\hline \multicolumn{3}{|c|}{$\begin{array}{l}\text { Quantidade de livros lidos (todo ou em parte) nos anos de } 2011 \\
\text { e } 2015\end{array}$} \\
\hline REGIÃO & 2011 & 2015 \\
\hline NORTE & 1,51 & 2,44 \\
\hline NORDESTE & 2,00 & 2,15 \\
\hline
\end{tabular}




\begin{tabular}{|l|l|l|}
\hline SUL & 1,51 & 2,05 \\
\hline SUDESTE & 1,84 & 2,98 \\
\hline CENTRO-OESTE & 2,12 & 2,52 \\
\hline Média & $\mathbf{1 , 7 9 6}$ & $\mathbf{2 , 4 2}$ \\
\hline
\end{tabular}

Fonte: SEGS, 2018, s.p. (Adaptado por LISBOA, 2018).

A tabela mostra um crescimento no período de 4 (quatro) anos, destacando a Região Sudeste como a que possui maior número de leitores, o que não espanta, pelo fato de possuir um maior número de editoras e um marketing mais fervoroso no assunto.

\section{DESAFIOS E POSSIBILIDADES ACERCA DO ENSINO DE LITERATURA PARA ESTUDANTES DO ENSINO MÉDIO NA ERA TIC}

O Ensino Médio corresponde à etapa final da Educação Básica, coincidindo com o momento de uma escolha profissional, a independência legal, o [possíve] ingresso no Ensino Superior. Estas são decisões que agridem ao estudante e ao afirmar isto, coloca-se como um fato que exige uma postura destes diante de suas futuras escolhas como sujeitos de direito. Referente aos processos de ensino e aprendizagem, nos últimos tempos, a reclamação dos professores tem sido muito ampla no sentido de que os estudantes não se interessam bem como o rendimento alcançado, de modo genérico, não tem atendido ao esperado, não alcançando, assim, as metas planejadas. Soma-se a isto, o desinteresse dos estudantes pelos conteúdos ministrados em classe, agravando a situação didático-pedagógica.

Tal situação de enfrentamento desta problemática faz surgir necessidades de elaboração de estratégias que permitam solucionar o problema da forma mais técnica possível. Neste contexto cabe ao professor atuar por meio de atividades didáticas e pedagógicas que possibilitem ao estudante desenvolver o seu potencial de estudos e alcançar os objetivos propostos no currículo escolar.

O ensino de qualquer disciplina está atrelado, diretamente, à capacidade didática de quem o aplica sobre o objeto a que se destina. Não adianta ter recursos à disposição, 
metodologias de última geração, estratégias maravilhosas que tudo isto tende a perder-se no vácuo da inocuidade científica ou didática, ou seja, não provocará nenhuma mudança de postura ou de pensamento em quem está a aprender.

Para ensinar com categoria para qualquer modalidade de ensino há que conhecer a fundo o objeto, sua psicologia, seus procedimentos, como pensa em dado momento, que ferramentas utilizam para alcançar seus objetivos e o que esperam. No Ensino Médio, em que os estudantes são adolescentes, isto é mais necessário porque são dados a conhecer em profundidade assuntos de alta complexidade, a formular teorias que solucionariam os problemas dados com muita facilidade e a desafiar o professor. Esta seria a primeira estratégia de ação para ensinar Literatura no Ensino Médio, porque, em tempos de internet e redes sociais (ERA TIC) em que a informação vulgar e a sabedoria convencional caminham à velocidade do vento, o professor deve preparar-se mais do que o necessário porque irá defrontar, ao vivo e em tempo real com pareceres de diversos especialistas, que serão clicados por seus alunos durante a sua aula.

Quando se aborda, especificamente o ensino de literatura, tem-se que analisar, de antemão, a capacidade científica dos alunos em discorrer sobre os textos literários, olhando-os a certa distância, fazendo comparações com outros textos e com os momentos da história e com a história de povos mais adiantados nos termos que se está a analisar. O recurso já estaria dado, a metodologia seria a analítica comparativa e a estratégia a utilização dos meios de comunicação em massa, como a internet, os telejornais, os jornais impressos, vídeos, livros de história política, críticas, crônicas e artigos pulicados em diferentes momentos políticos da história, considerando que o estudo literário compreende conhecer toda a rede que compõe a estrutura em torno da obra, objeto de estudo analítico.

Assim que, a primeira possibilidade é a de uso das mídias eletrônicas como forma de angariar o máximo possível de informações e trabalhá-las em tempo real com os estudantes em sala, ou nos espaços pedagógicos. Para isto, o professor deve ter formação sólida, conhecimento de causa, tecer um planejamento adequado às exigências reais da disciplina e seus objetivos. 
Na concepção de Castro e Garrossino,

Com relação aos métodos a serem adotados para o desenvolvimento da aprendizagem e assimilação dos conteúdos por parte dos alunos neste tipo de organização de ensino, seria interessante dar prioridade aos que promovam a relação das dimensões do saber: teoria e prática; concepção e execução; cultura e técnica; atividade intelectual e manual, sempre tendo como ponto de partida para a aquisição de novos conhecimentos a realidade do aluno (CASTRO e GARROSSINO, 2010, p. 96).

Deve-se tomar muito cuidado quando se afirma que a realidade do estudante deve ser o ponto de baliza para os trabalhos. Isto demonstra despreparo intelectual da parte de quem afirma tal coisa e para agregar, falta-lhe preparo metodológico prévio e tal afirmação conduz muitos professores a querer, primeiro conhecer a turma, para depois elaborar alguma coisa e terminam por não fazer nada, porque descobre que o nível de seus alunos é sofrível. O trabalho didático é algo pensado fora da sala de aula, tendo como fundamento, o prescrito no currículo e os estudos realizados por cientistas de renome, por meio de testes já validados pela comunidade científica. $\mathrm{Na}$ lide diária, o que se faz premente é que este planejamento prévio vá sendo adequado às exigências particulares e singulares do grupo. Referente ao ensino de Literatura, caso os estudantes não possuam o hábito da leitura, isto não quer dizer que não se possa trabalhá-la. Para isto, ele terá que realizar um trabalho de base, mais longo e se havia elaborado objetivos muito amplos, deve reconsiderá-los, mas tendo em vista que seu papel é o de ensinar, de possibilitar a saída do indivíduo de sua condição de minoridade para uma condição de maioridade, ou seja, proporcionar-lhe o esclarecimento, segundo a concepção de Kant (1803).

As dificuldades surgem quando os estudantes se negam a desenvolver a autonomia acadêmico-científica, quando não querem e passam a boicotar o que lhes é oferecido. Se isto ocorre, toda a estrutura metodológica fica comprometida e não haverá recursos que possam ser utilizados para conferir ganhos de aprendizagem reais. Muitas vezes, os textos e romances ou obras literárias lidas conflitam com seus 
mundos em desenvolvimento e confusos, o que gera resistências as quais o professor desprovido de conhecimento psicológico acerca da psique adolescente interpreta estas negações como indolência, rebeldia. Isto gera conflitos onde não haveria necessidade de existir, perdendo ótimas possibilidades de execução de sua práxis, da maneira mais didática possível.

O que se está a discutir é que, como o público do Ensino Médio já é composto por adolescentes, que por natureza já assumem posturas rebeldes e de desafio aos projetos e aos professores, o fazer pedagógico se torna muito mais desafiador e por vezes, estressante. Estão sempre aprisionados ao celular e à internet e este se torna o maior desafio para o professor, que é fazer com que encontrem prazer e satisfação com os estudos e para tanto, não necessitam abandonar as ferramentas inovadoras de comunicação e informação, transformando-as em aliadas.

Especificamente, com relação ao ensino de Literatura, o professor deve tomar todo o cuidado em escolher as obras que atendam aos interesses imediatos dos seus estudantes. Após este primeiro contato, ir, aos poucos inserindo os clássicos, ao mesmo tempo em que aprofunda na explanação dos conteúdos, na tentativa de despertar o interesse e a paixão pelo saber e pelas obras declaradas como didáticas no currículo educacional, que se configura como a base do planejamento educacional. Portanto,

O que se está preconizando é a criação de condições para nutrir os sujeitos em processos de formação com um conjunto de saberes necessários à análise de conceitos e ao desenvolvimento de atitudes e de habilidades desejáveis à tomada de decisões e de posições sobre o processo de ensino e de aprendizagem, tendo em vista as possibilidades de redimensão e melhoria desse processo, em consonância com as exigências estabelecidas a partir das suas opções científicas conscientes (CASTRO e GARROSSINO, 2010, p. 99-100)

Este pode ser um ponto crucial, porque caso o estudante não possua uma base científica que lhe confira suporte epistemológico, esta deve ser construída, fato que 
leva tempo e necessidade de dedicação de ambas as partes. Há que definir o que são atividades mediadoras e atividades fins e, a partir disto, elencar o que se apresenta como dificuldades, o que se mostra como possibilidades e, aquilo que se interpreta como potencialidades.

\section{CONCLUSÃO}

O ensino de literatura é um dos mais fantásticos a que se pode dar a condição de praticar, como docente, porque ele, por si só, constitui-se como um desafio [aparentemente] insolúvel e à medida que se imerge no processo, conhecendo e se apropriando do objeto, mas ele mostra-se pragmático e repleto de possibilidades, o que o caracteriza como um saber que ensina e aprende.

Com o advento das TIC's e sua imponente inserção no meio educacional, surgem dificuldades, em um primeiro momento, críticas severas a ela e uma bateria de produções, que visem difamá-la, quando, o mais acertado seria a elaboração de um conjunto de ações didáticas, pedagógicas e metodológicas que possibilite ao professor desenvolver com maior autonomia seus procedimentos técnicos de ensino e, ao estudante atingir maiores e melhores níveis de aprendizagem.

O maior desafio posto ao ensino da Literatura é a dificuldade e a resistência que os estudantes apresentam para ler textos de caráter teóricos, literários e ainda mais para interpretar o que eles proporcionam como condições de produção de saberes e conhecimentos úteis à sociedade. Não se trata de analfabetismo funcional, antes de não apresentar interesse em ler as entrelinhas do que está posto, como objeto de estudo, análise, interpretação e compreensão, o que conduz como afirma Jaspers ao conhecimento objetivo, em si.

Os recursos tecnológicos de informação e comunicação proporcionaram incrementos incríveis nos campos da Literatura, tanto em termos técnicos, didáticos, pedagógicos e sociais, porque possibilitam a aproximação do indivíduo com os objetos de sua curiosidade. Portanto, isto é algo que deve ser explorado, o máximo, pelo professor, 
porque representam oportunidades únicas de encontro e reencontro com seus anseios, medos, desafios, potencialidades, alegrias, angústias e expectativas.

Como desafio principal neste momento histórico, na ERA TIC, para o ensino da Literatura está à necessidade de ser ter instrumentos adequados à necessidade que se apresenta e não mais adequados à realidade acadêmica. No máximo, pode-se afirmar que a realidade epistemológica possa ser quem esteja a ditar os rumos desta nova forma de ver e de pensar o ensino e a aprendizagem de Literatura. Para isto, necessita-se de uma nova leitura, que permita aproximar do que se espera alcançar por meio do trabalho didático focado nas possibilidades, uma vez que os desafios estão sempre à mostra.

Outro ponto a ressaltar é que as TIC's são elementos que podem ser transformados em instrumentos de trabalho didático, pois, elas não são nem nunca serão ferramentas educacionais, cabe, portanto, aos professores darem tal destinação às mesmas, por meio do desenvolvimento de metodologias ativas, eficientes e eficazes.

Com relação ao Ensino Médio e o ensino de Literatura, sem conhecer a psicologia do objeto, ter uma ideia do público com o qual se pretende inserir os conteúdos e as formas, fica muito difícil alcançar o resultado esperado. Todo o processo deve seguir linhas estratégicas de pensamento, sabendo que os desafios de ensino são portas de acesso para possibilidades de criação, análise, estudos, interpretação e compreensão de novas metodologias de ensino.

\section{REFERÊNCIAS}

CANIÇALI, Mônica Nadja Silva d'Almeida; SOUZA, Sérgio Rodrigues de. El lugar docente como fundamento epistemológico de la praxis pedagógica en la ERA TIC. Anais do II Congresso Internacional de Educação e Tecnologias. São Carlos: Universidade Federal de São Carlos, 2018.

CASTRO, R. M.; GARROSSINO, S. R. B. o Ensino Médio no Brasil: organização do trabalho e educação. ORG \& DEMO, Marília, v.11, n.1, p. 91-102, jan./jun., 2010. 
GUIMARÃES, Paula. Retratos da Leitura - Perfil do Leitor. (26 de julho de 2017). Disponível em: https://www.institutoguimaraes.com.br. Acesso em 14 de dezembro de 2018, às 13:04h.

JASPERS, Karl. La filosofía. México: Fondo de Cultura Económica, 1991.

KANT, I. Resposta à Pergunta: O que é Esclarecimento? São Paulo: Edusp, 2009. [Este texto es una respuesta encaminada al reverendo Sr. Zöllner, en respuesta a la pregunta por él elaborada y publicada en el periódico Berlinischer Monatschrifft, en la data de 05 de diciembre de 1783, seguida por el comentario que la acompaña: ¿Qué es el esclarecimiento? Esta cuestión es aproximadamente la siguiente: ¿Qué es la verdad? ¡Se hace necesario responder a esta cuestión para que el hombre se juzgue esclarecido! ¡Y aún no miré ningún individuo que tenga respondido a esto! El Sr. Inmanuel Kant encaminó su respuesta al periódico en 30 de septiembre de 1784].

MIKULINSKIY, S. P. Ciencia, Historia de la Ciencia, Cienciología. Recopilación de artículos. Editorial Academia: La Habana, 1985.

NUNES, Antônio Vidal. Metodologia da pesquisa educacional [recurso eletrônico]. Vitória, ES: Universidade Federal do Espírito Santo, Secretaria de Ensino a Distância, 2018.

SEGS. Pesquisa retratos da leitura no brasil revela hábitos de leitura de cada um dos estados brasileiros. (26 de maio de 2017). Disponível em: https://www.segs.com.br/educacao/65853. Acesso em 14 de dezembro de 2018, às 13:04h.

SILVA, Antonio de Pádua Dias da. 0 ensino de literatura hoje: da crise do conceito à noção de escritas. Coleção Ensino \& Aprendizagem. Volume 1. Campina Grande: Eduepb, 2016.

TODOROV, Tzvetan. A literatura em perigo. Rio de Janeiro: Difel, 2009. 
VALENTE, J. A. A Espiral da Espiral de Aprendizagem: o processo de compreensão do papel das tecnologias de informação e comunicação na educação. Tese (Livre Docência). Instituto de Artes da Universidade Estadual de Campinas. Campinas: UNICAMP, 2005.

Enviado: Junho, 2020.

Aprovado: Junho, 2020. 